\title{
Image-guided thermal ablation might be a way to compensate for image deriving cancer overdiagnosis
}

\section{Giovanni Mauri \& Luca Maria Sconfienza}

To cite this article: Giovanni Mauri \& Luca Maria Sconfienza (2016): Image-guided thermal ablation might be a way to compensate for image deriving cancer overdiagnosis, International Journal of Hyperthermia, DOI: 10.1080/02656736.2016.1262969

To link to this article: $h$ ttp://dx.doi.org/10.1080/02656736.2016.1262969

Accepted author version posted online: 20 Nov 2016.

Submit your article to this journal $\sqsubset$

Џll Article views: 2

Q View related articles $\sqsubset$

View Crossmark data ¿ 


\section{Image-guided thermal ablation might be a way to compensate for image deriving cancer overdiagnosis}

Dr. giovanni mauri* -Istituto Europeo di Oncologia, Division of Interventional Radiology, Milano, Italy

Prof. Luca Maria Sconfienza- IRCCS Istituto Ortopedico Galeazzi, Milano, 20100 Italy ;

Dipartimento di Scienze Biomediche per la Salute, Università degli Studi di Milano, Milan, Italy

*Corresponding Author - vanni.mauri@gmail.com

Dear Sirs,

we read with great interest the paper by Kim et al. entitled "Radiofrequency ablation of low-risk small papillary thyroidcarcinoma: preliminary results for patients ineligible for surgery" recently published in the International Journal of Hyperthermia [1]. In this paper, Authors reported on the successful treatment of six patients with small papillary thyroid carcinoma (PTC) with radiofrequency ablation. This paper provides an extremely interesting and novel point for discussion in the actual debate regarding diagnosis and treatment of small PTCs.

Thanks to the improvement in imaging techniques and interventional skills, thyroid nodules as small as few millimeters can be detected and biopsied, making easier to diagnose thyroid cancers in their very initial phase [2]. Unfortunately, early diagnosis of a cancer does not always represent a benefit for the patient. It may happen that a cancer is detected so early, in a situation in which is so indolent or stable that it would not have become evident during the subject's life without the medical act of preclinical detection. This may occur either because the cancer does not progress or because the rate of progression is so slow that the patient dies of other causes before it determines any symptoms. These cases can be reported as overdiagnosis. This phenomenon is of particular 
relevance when dealing with thyroid cancers, where the most prevalent by far is papillary subtype, a very indolent kind of tumor with a good prognosis and a reported nearly-95\% 30-year survival [3]

Moreover, detection of a cancer determines great anxiety in patients, and always trigger intensive treatment. As a consequence, the number thyroidectomies performed after early detection has risen, with a related increase in costs, anxiety for patients, and potential complications [4]. However, when a treatment is provided for a disease that would have never affected the patient life, this can be regarded as overtreatment. The problem of overdiagnosis and overtreatment is so relevant in thyroid cancer that some authors provocatively proposed to turn off ultrasound machine in order to avoid it [5].

On the other hand, once a tumor is discovered, we are somewhat compelled to do something for it. In this setting, trying to minimize overdiagnosis (by improving imaging differential diagnosis or molecular diagnosis) seems to be extremely challenging. A different option might be to reduce the overtreatment by decreasing the treatment invasiveness. Some authors suggested offering the patients with low risk tumor active surveillance in place of immediate resection [6]. However, it is highly probable that only a small minority of patients would accept active surveillance instead of surgery once diagnosed with a tumor.

In this scenario, imaging-guided therapies may play a crucial role, representing less invasive alternatives to surgery, thus being able of offering a treatment to the patients, but lowering its invasiveness. Image-guided tumor ablation has been successfully reported in several different organs (e.g. liver, kidney, lung), and in some cases ablation is now recommended as the first choice treatment in international guidelines. Regarding image guided thermal ablation for thyroid disease, the vast majority of the literature is focused on the treatment of benign thyroid nodules [7-12], while experiences of treating malignant disease are very limited, and mainly dealing with recurrences after surgical treatment [13-17]. Conversely, the potential of image-guided ablation in the treatment of primary thyroid tumors has been investigated by few authors in small series [18- 
20]. In this scenario, the paper by Kim et al. [1], reporting on the positive follow up at a mean of 48 months after ablation of small PCTs provide a valuable evidence on safety and effectiveness of this approach as an alternative to surgery and active surveillance.

Last but not least, an interesting debate is ongoing about the systemic effect of local tumor ablation, as it is not clear whether local treatments may induce regression of distant metastases or may favour disease progression[21, 22]. This may be of particular interest in patients with other types of thyroid cancer with distant metastases in whom surgery is not indicated and local ablation is performed as the only palliative treatment .

In conclusion, the radiological community should be aware that the problem of overdiagnosis cannot be regarded as negligible and may be reduced eliminating inappropriate imaging. However, interventional radiologists should play a crucial role, trying to compensate overdiagnosis by reducing the aggressiveness of treatment and its unavoidable complications. Thus, we envision a scenario were minimally invasive percutaneous treatments will play an increasingly important role reducing the aggressiveness of treatments, possibly being the solution to compensate for the morbidity and mortality related to overdiagnosis and consequent overtreatment. This perspective is very close to come, but it must be accompanied by high-quality research demonstrating the effectiveness of these mini-invasive treatments over conventional surgical approaches. 
References

1. Kim J-H, Baek JH, Sung JY, et al. (2016) Radiofrequency ablation of low-risk small papillary thyroidcarcinoma: preliminary results for patients ineligible for surgery. Int $\mathbf{J}$ Hyperthermia 1-11. doi: 10.1080/02656736.2016.1230893

2. Brito JP, Morris JC, Montori VM (2013) Thyroid cancer: zealous imaging has increased detection and treatment of low risk tumours. BMJ 347:f4706.

3. Jemal A, Murray T, Ward E, et al. Cancer statistics, 2005. CA Cancer J Clin 55:10-30.

4. Sun GH, DeMonner S, Davis MM (2013) Epidemiological and economic trends in inpatient and outpatient thyroidectomy in the United States, 1996-2006. Thyroid 23:727-33. doi: 10.1089/thy.2012.0218

5. Cronan JJ (2008) Thyroid Nodules: Is It Time to Turn Off the US Machines? Radiology 247:602-604. doi: 10.1148/radiol.2473072233

6. Ito Y, Miyauchi A, Inoue H, et al. (2010) An observational trial for papillary thyroid microcarcinoma in Japanese patients. World J Surg 34:28-35. doi: 10.1007/s00268-0090303-0

7. Pacella CM, Mauri G, Achille G, et al. (2015) Outcomes and Risk Factors for Complications of Laser Ablation for Thyroid Nodules: A Multicenter Study on 1531 Patients. J Clin Endocrinol Metab 100:3903-3910. doi: 10.1210/jc.2015-1964

8. Lim HK, Lee JH, Ha EJ, et al. (2013) Radiofrequency ablation of benign non-functioning thyroid nodules: 4-year follow-up results for 111 patients. Eur Radiol 23:1044-9. doi: $10.1007 / \mathrm{s} 00330-012-2671-3$ 
9. Jeong WK, Baek JH, Rhim H, et al. (2008) Radiofrequency ablation of benign thyroid nodules: safety and imaging follow-up in 236 patients. Eur Radiol 18:1244-50. doi: $10.1007 / \mathrm{s} 00330-008-0880-6$

10. Mauri G, Cova L, Monaco CG, et al. (2016) Benign thyroid nodules treatment using Percutaneous Laser Ablation (PLA) and Radiofrequency Ablation (RFA). Int J Hyperthermia 1-17. doi: 10.1080/02656736.2016.1244707

11. Heck K, Happel C, Grünwald F, Korkusuz H (2015) Percutaneous microwave ablation of thyroid nodules: effects on thyroid function and antibodies. Int J Hyperthermia 31:560-7. doi: $10.3109 / 02656736.2015 .1032371$

12. Negro R, Salem TM, Greco G (2016) Laser ablation is more effective for spongiform than solid thyroid nodules. A 4-year retrospective follow-up study. Int J Hyperthermia 32:822-8. doi: 10.1080/02656736.2016.1212279

13. Mauri G, Cova L, Ierace T, et al. (2016) Treatment of Metastatic Lymph Nodes in the Neck from Papillary Thyroid Carcinoma with Percutaneous Laser Ablation. Cardiovasc Intervent Radiol 39:1023-30. doi: 10.1007/s00270-016-1313-6

14. Baek JH, Kim YS, Sung JY, et al. (2011) Locoregional control of metastatic welldifferentiated thyroid cancer by ultrasound-guided radiofrequency ablation. AJR Am J Roentgenol 197:W331-6. doi: 10.2214/AJR.10.5345

15. Yue W, Chen L, Wang S, Yu S (2015) Locoregional control of recurrent papillary thyroid carcinoma by ultrasound-guided percutaneous microwave ablation: A prospective study. Int J Hyperthermia 31:403-8. doi: 10.3109/02656736.2015.1014433

16. Mauri G, Cova L, Tondolo T, et al. (2013) Percutaneous laser ablation of metastatic lymph nodes in the neck from papillary thyroid carcinoma: preliminary results. J Clin Endocrinol 
Metab 98:E1203-7. doi: 10.1210/jc.2013-1140

17. Kim J, Yoo WS, Park YJ, et al. (2015) Efficacy and Safety of Radiofrequency Ablation for Treatment of Locally Recurrent Thyroid Cancers Smaller than $2 \mathrm{~cm}$. Radiology 276:909-18. doi: 10.1148/radiol.15140079

18. Papini E, Guglielmi R, Gharib H, et al. (2011) Ultrasound-guided laser ablation of incidental papillary thyroid microcarcinoma: a potential therapeutic approach in patients at surgical risk. Thyroid 21:917-20. doi: 10.1089/thy.2010.0447

19. Valcavi R, Piana S, Bortolan GS, et al. (2013) Ultrasound-guided percutaneous laser ablation of papillary thyroid microcarcinoma: a feasibility study on three cases with pathological and immunohistochemical evaluation. Thyroid 23:1578-82. doi: 10.1089/thy.2013.0279

20. Yue W, Wang S, Yu S, Wang B (2014) Ultrasound-guided percutaneous microwave ablation of solitary T1N0M0 papillary thyroid microcarcinoma: initial experience. Int J Hyperthermia 30:150-7. doi: 10.3109/02656736.2014.885590

21. Chapiro J, Geschwind J-F (2015) Science to Practice: The Changing Face of Local Tumor Therapies-Do We Have to Think Systemically When Treating Cancer Locally? Radiology 276:315-7. doi: 10.1148/radiol.2015150451

22. Mauri G, Orsi F, Sconfienza LM (2016) Systemic Effects of Local Tumor Ablation: Oncogenesis and Antitumor Induced Immunity. Radiology 279:322-3. doi: 10.1148/radiol.2016151739 